\title{
Mining Ground Surface Information Extraction and Topographic Analysis Using UAV Video Data
}

\author{
Yin Yaqiu ${ }^{I}$, Jiang Cunhao ${ }^{I}$, Lv Jing ${ }^{2, *}$, Wang Jie ${ }^{1}$, Ju Xing ${ }^{I}$, Wang Hao ${ }^{1}$, Xing Yu ${ }^{l}$ and Zhang Lushou ${ }^{1}$ \\ ${ }^{1}$ China Aero Geophysical Survey \& Remote Sensing Center for Land and Resources, Beijing 100083 \\ ${ }^{2}$ Land Consolidation and Rehabilitation Center, Ministry of Natural Resources, Beijing 100035
}

\begin{abstract}
Taking the Xiangwang bauxite mining of Xiaoyi City, Shanxi Province as the research object, the DJi "Wu"inspire2 model Unmanned aerial vehicle (UAV) was used to obtain the video data, image data and Ground control points (GCP) data of a typical pit in the study area. Based on the two kinds of data source (video data and image data), the Digital surface model (DSM) of the research area was acquired with or without ground control points through aerial triangulation and block adjustment. Using the DSM obtained by the two data source, the distribution of elevation, slope, slope direction, surface fluctuation and surface roughness was extracted and compared. Research shows that the DSM, acquired by the ContextCapture software without GCP, using video data obtained by aerial shooting around one interest point, can qualitatively reflect the topographic distribution of the land surface. The DSM got by the video data with the GCP can achieve the similar accuracy with the result obtained by image data, and the topographic information acquired by the two kinds of data source has highly similar characteristics in spatial and numerical distribution. It can be concluded through comparison and analysis of the topographical factors that steep slopes with complex topography and large elevation difference distributes in the northwest-central of the pit, of which northwest and southwest slopes can be easily eroded by wind and rain, so attention should be paid to slop stability monitoring and disaster prevention in this area. As a whole, the results show that video data obtained by UAV can not only reflect the dynamic changes of the land surface qualitatively, but also can describe the distribution of surface topography quantitatively through processing to get the DSM. It has great application potential in the field of disaster emergency monitoring and geological hazard risk assessment in mining areas.
\end{abstract}

\section{Introduction}

Mineral resources are the fundamental basis of a country's economic and social development, and also one of the significant symbols of a country's national power [1]. Opencast mining is the main way of mining. According to statistics, more than $90 \%$ of the mines with a capacity of over 10 million tons per year are open-pit mines [2]. Opencast mining can cause damage to the surface environment, make the original land barren, accelerate soil erosion and land desertification. Furthermore, under the action of human and nature, high and steep slopes of mining pits and waste heaps, can cause collapse, landslide, debris flow and other geological disasters. It poses a threat to the personal and property safety of mining personnel and surrounding residents and is the key concern of mine safety.

Obtaining the three-dimensional distribution information of the open-pit mine surface can monitor the stability of the potential disaster area, and provide basic geographic data for the subsequent ecological restoration. Traditional methods of mine topographic survey include GPS measurement and total station measurement. Although the accuracy is higher, the methods can only be used for single point measurement, so that they are not suitable for mines of complex terrain. The development of aerial photogrammetry makes noncontact measurement become possible. Using remote sensing technology to obtain three-dimensional information of mining area greatly saves labor cost and avoids the potential danger of working in disaster-prone areas. UAV remote sensing is one of the most convenient means of aerial photogrammetry, which has the characteristics of high efficiency and low cost [3].

Sui T, Xiao W, Wang D C et al used the UAV to obtain images with three relative altitudes $(85,100$ and $115 \mathrm{~m}$ ) of Shengli West No.1 open-pit coal mine and two softwares(Pixe4D mapper and Agisoft PhotoScan) were used to deal with the images with different relative altitudes to obtain the DSM and Digital Orthophoto Map(DOM). Results show that Pixe4D mapper software has higher modeling accuracy and the model accuracy of the three altitudes all can meet the mapping requirements of 1:1000 map and topographic map, among them, the accuracy and reliability of DSM and DOM with $100 \mathrm{~m}$ relative altitude are superior to others, therefore, the 1:500 map drawing requirement can be met [4]. Taking an open-pit quarry in Zhoushan as the engineering

\footnotetext{
*Corresponding author: yinyaqiu@,126.com
} 
background, Fang X, Zhang Z L and Wang L G et al used Pix4D mapper to effectively analyze and process the data of UAV and large amount of orthophoto data acquired. They quickly and conveniently obtained the three-dimensional information of mining area, and generate the DSM and DOM. Results show that UAV aerial survey can reconstruct the $3 \mathrm{D}$ model of mining area at a certain stage, and realize the $3 \mathrm{D}$ panoramic roaming of mining area [5].

These above studies are all based on aerial images and ground control points of research areas to reconstruct the $3 \mathrm{D}$ surface model. However, the ground needs to make rapid response in case of disaster emergency, and it is impossible to get the ground survey control point in areas that is dangerous and inaccessible in reality. Some researchers then have explored data processing methods of UAV without control points. TIAN, CHEN,LI chose Baichagoumen village, Qingyang City, Gansu Province as the experimental area and used Topcon Sirius PRO UAV to obtain images quickly. The real-time accurate position was obtained through the integration of precise time measurement technology and carrier phase difference technology, which realized the automatic and rapid construction of DSM without control points. The accuracy testing shows that mean square error in planar is about 2 times of GSD, and that of height is within 3 times of GSD, which can meet the accuracy requirements of 1:500 mapping specification [6]. Gong A D, He X Y, Lei T J et al. took the earthquake-stricken area in Sichuan Province as research area and applied SIFT algorithm to UAV image matching. The method can realize high-performance image processing and large-area image correction, by combining image mosaic method with the auxiliary information recorded by UAV system. Results show that the main surface features have no visual errors [7].

These studies are all based on aerial images to obtain surface information. With the development of remote sensing and the demand of continuous dynamic object monitoring in application, video satellite data and video flight data have been gradually applied in the fields such as natural disaster emergency response, law enforcement and supervision of mineral resources exploitation and military security. The UAV equipped with video camera does not have to consider the overlap of heading direction, exposure interval and other factors before aerial photographing. So it can acquire the dynamic data of the ground quickly and has the advantages of high mobility and low cost by comparing with the video satellite.

The video sensor continuously adjusts the perspective to realize the staring observation for the fixed area, which can equivalently obtain the image sequence with continuously changing observation angles of this area. By resampling each frame, stereopairs of the stationary images can be acquired, which meets the requirements of generating the DSM. The use of UAV video data to obtain the surface elevation distribution information can not only qualitatively get dynamic changes in the natural disaster area, but also can quantitatively describe the surface deformation in the disaster area, providing technical support for natural disaster monitoring and assessment.

This article selects Xiangwang bauxite mine in Lvliang City, Shanxi Province as the research area, taking advantage of UAV to shoot videos and images of the mining, using BeiDou GPS to measure the ground control points. Based on the UAV video data and image data, the DSM is acquired and the accuracy of the results obtained by the two methods is analyzed and evaluated, so as to get the feasibility of UAV video data in emergency monitoring.

\section{Overview of the study area}

The research area was chose in Xiangwang bauxite mine, Xiaoyi City, Shanxi Province. Xiangwang bauxite mine is located in Xiangwang village, Nanyang Township. The south side of the mining is adjacent to provincial highway S340 and the north side is close to national highway 307 and Fenjun expressway. It is formed by the integration of three mining areas--Xiangwang mining area $\left(1.2557 \mathrm{KM}^{2}\right)$ in former Aluminum Co. of China Ltd., Shanxi Branch, prospecting area of Xiangwang bauxite mining area $\left(4.74 \mathrm{KM}^{2}\right)$ and Quanxing bauxite mine $\left(0.25 \mathrm{KM}^{2}\right)$ of Xiaoyi city. The present mining has the area of $5.99 \mathrm{KM}^{2}$, adopting open-pit mining, with a planned production capacity of 600000 tons per year.

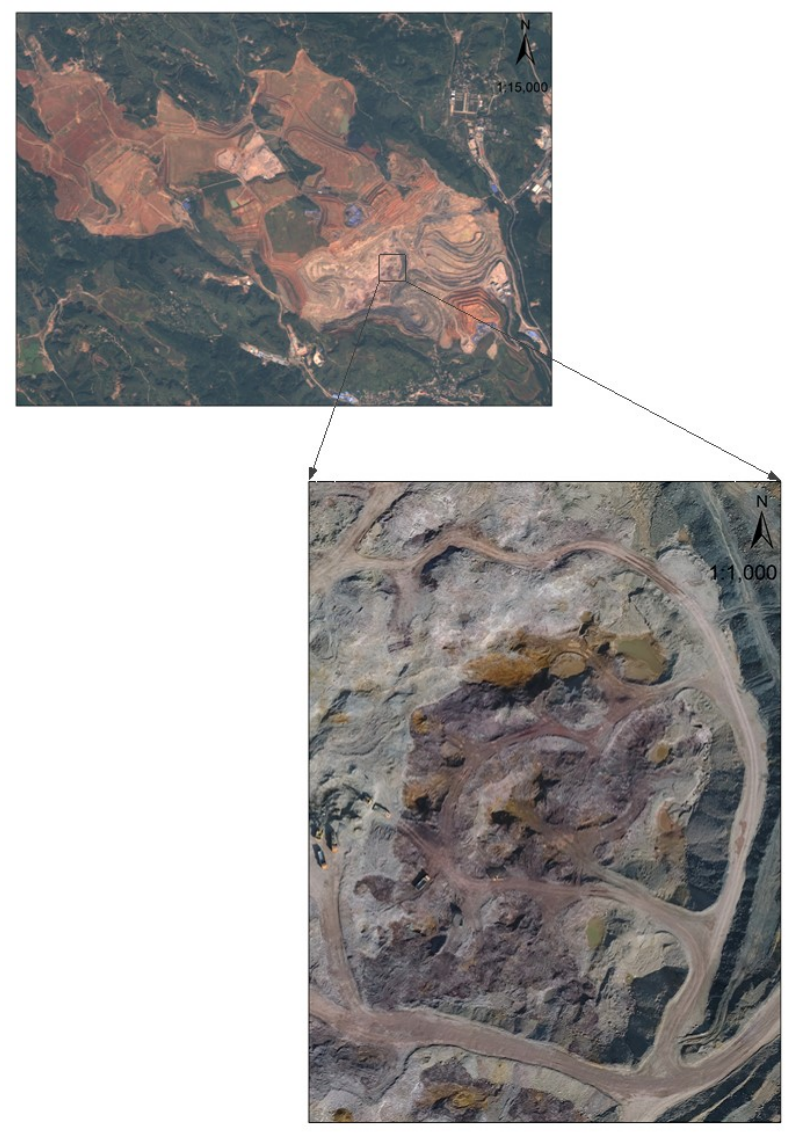

Fig. 1. Overview of the study area.

The mining is located in the eastern side of Lvliang Mountain, and the physiognomy type belongs to erosional landform middle-mountain area. The terrain is 
high in the West and low in the East on the whole. Raines and gullies criss-cross in the area with large topographic relief. The slope of hillside is generally 25 $30^{\circ}$, and bedrocks are exposed at some steep terrain areas. It belongs to the temperate continental monsoon climate, four distinct seasons, with an annual average temperature of $10.1{ }^{\circ} \mathrm{C}$. The average annual rainfall is $438.4 \mathrm{~mm}$, mostly concentrated in July, August and September. The dominant wind direction of it is westerly, mainly southwest wind and northwest wind. In this paper, the mining pit on the south side of the mining is selected as the research object, and the distribution of the mining pit is shown in Fig. 1. Covering an area of 60000 square meters, there are several roads for transportation around and inside the pit. Land surface of the pit is uneven and has large topographic relief, which could easily lead to landslides, collapses and other geological disasters

\section{Acquisition and analysis of the land surface information}

The DJi "Wu"inspire2 model UAV, which is equipped with Zenmuse X5S camera, was used to obtain the video and image data of the research area. Axle distance of the UAV is $605 \mathrm{~mm}$ and vertical and horizontal hovering accuracy is $0.5 \mathrm{~m}$ and $1.5 \mathrm{~m}$. Zenmuse X5S camera has both photo mode and video mode. With 20.8 megapixel, the camera can capture photos of $5280 \times 3956$ pixels and $5280 \times 2970$ pixels and record videos, single frame of which can reach $4096 \times 2160$ pixels, $5280 \times 2972$ pixels, $3840 \times 2160$ pixels, etc. Besides, the FOV of the camera is $72^{\circ}$ and shutter speed is $8-1 / 8000 \mathrm{sec}$.

In this study, the typical mine was chose as the research area, of which video data, image data and ground control point data was obtained. Based on the two kinds of data sources(video data and image data), the DSM of the research area was acquired with or without ground control points through aerial triangulation and block adjustment. The obtained results are analyzed qualitatively and quantitatively to reach a conclusion finally. The technique flow chart is shown as Fig. 2.

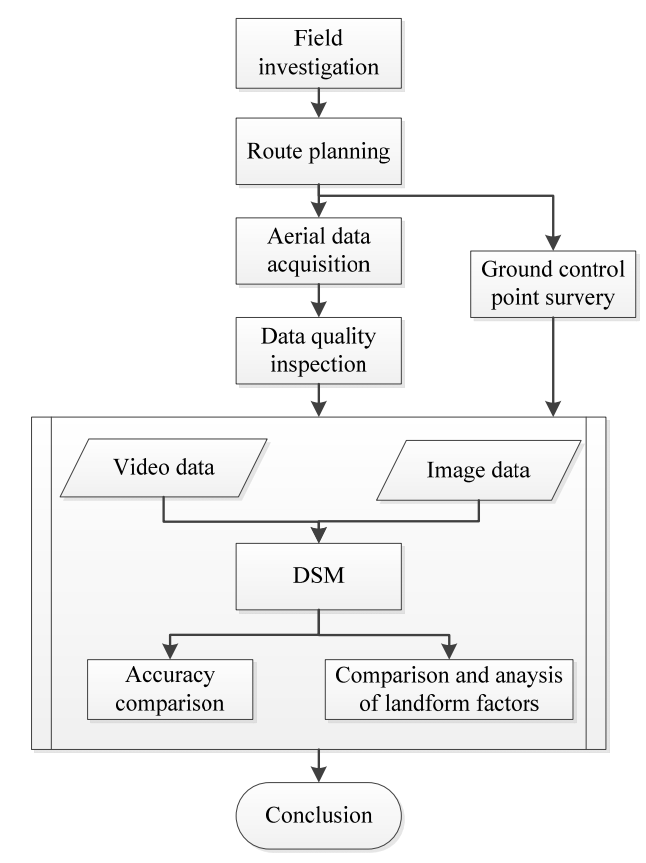

Fig. 2. Technique flow chart.

\subsection{Data collection}

The data was collected in the clear and cloudless days, with the surface temperature of $7-19{ }^{\circ} \mathrm{C}$ and west wind of 1-2 level. Two routes were designed to collect video data and image data. The video data collection route was designed to fly around the center of the pit (as shown in Fig. 3a) for two times, with the radius of $300 \mathrm{~m}$ and the flight height of $200 \mathrm{~m}$ and $300 \mathrm{~m}$ respectively. The total time of the obtained video data is 7 minutes and 6 seconds, with the frame rate of 29.97 FPS and per frame of $3840 \times 2160$ pixels. The image data collection route was designed to cover the whole mining area (as shown in Fig. 3b), which is 2.6 square kilometers. with the forward overlap of $80 \%$ and the sidelap of $60 \%, 293$ image data of $5280 \times 3956$ pixels were obtained. The data could be used after passing the quality inspection.

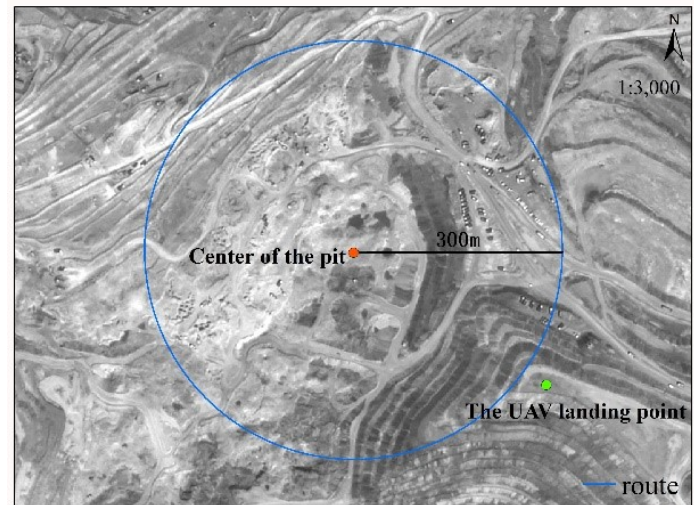




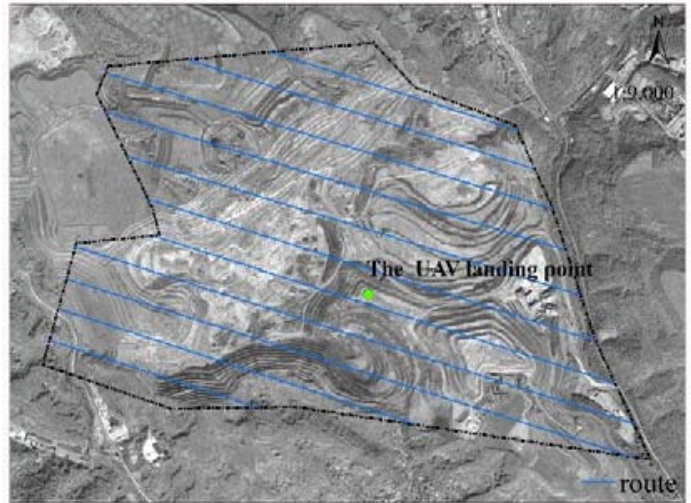

b

Fig. 3. Aerial data acquisition roadmap

Researches have shown that the DSM generated by aerial photography based on high-precision ground survey control points can achieve centimeter-level accuracy, which is sufficient to satisfy the application requirements of mine engineering [8-10]. Thus this article focuses on the comparison of the relative accuracy between two methods based on video data and aerial image data. 11 ground control points with obvious marks and texture feature at the edge or inside the pit were measured by using the YDA-22-10 on-board Beidou device. The distribution of ground control points is shown in Fig.4.

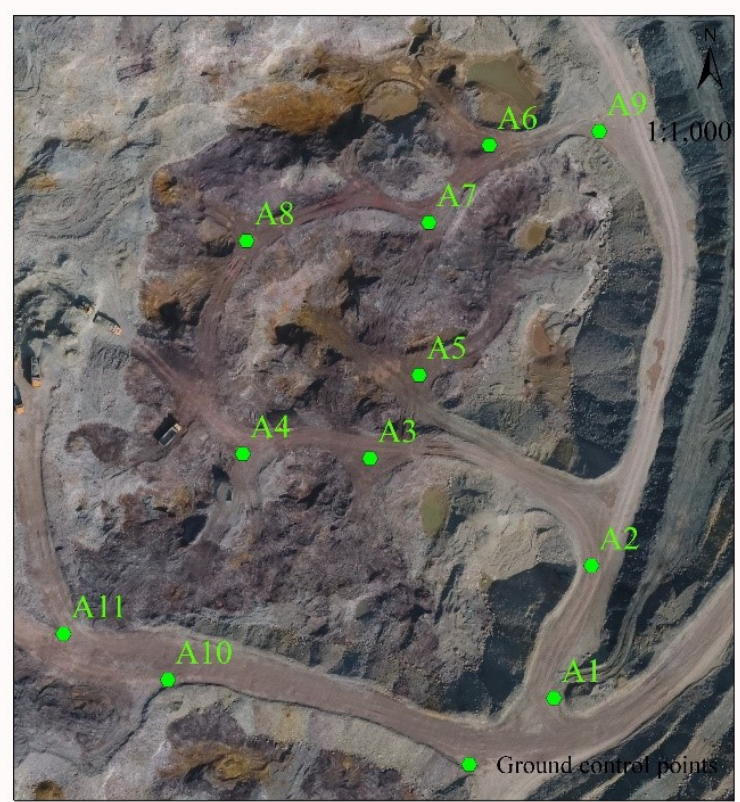

Fig.4. Distribution of the ground control points

\subsection{UAV aerial survey data processing}

The research uses ContextCapture to process the aerial survey data. ContextCapture software integrates the advanced digital image processing, computer virtual reality and geometry graphics algorithm modules, taking the lead in usability, data compatibility, and operational performance [11]. Using ContextCapture software, video data was segmented and resampled to obtain a series of frames with high overlap, based on which the homonymy points were extracted taking advantage of image feature matching algorithm. Using the homonymy points and ground control points, the three-dimensional solid model was constructed through the relative orientation, absolute orientation and bundle aerial triangulation of the frame series. The DSM was extracted from the three-dimensional solid model, finally.

The data was divided into two groups for processing. Group A is the UAV video data and group B is 293 aerial images. Choosing A1, A2, a7 and A8 as ground control points, the DSMs of the two sets of data were generated with or without ground control points respectively and the results are shown in Fig. 5.

DSM of the video data without control points has no coordinate information because the frames don't have positioning information. In order to compare the methods, it was calibrated to WGS84 coordinates manually. It can be seen form figure 5, the DSM obtained by the four methods can both qualitatively reflect the relative fluctuation characteristics of the land surface.

Range of the elevation obtained by the two data sources with the ground control points is basically the same. However, the elevation value of the video data without ground control points is the unit ratio of the relative elevation. The DSM obtained from image data without ground control points uses the GPS positioning information provided by UAV to get the elevation. So, the acquired elevation information can only reflect the relative height difference, and has low absolute elevation accuracy. In the following parts, it mainly focus on the comparison and analysis of the terrain factors extracted from the DSM of the two sets of data using ground control points.

Without ground control
points
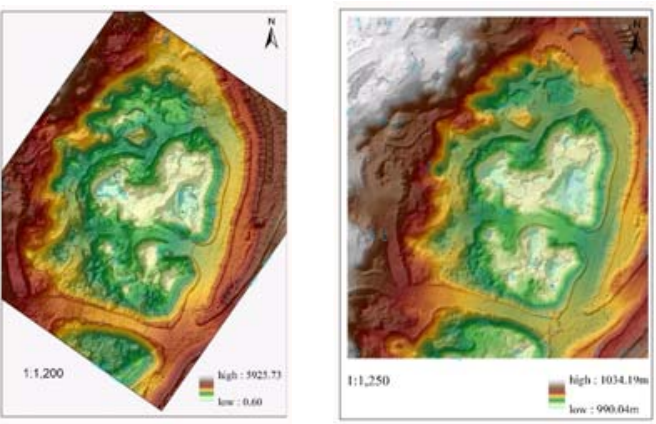

Video data
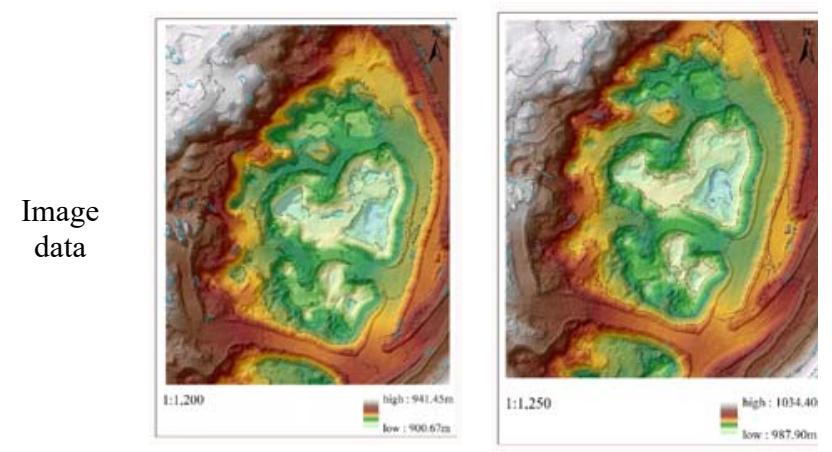

Fig. 5. The DSM figure 


\section{Comparison and evaluation}

\subsection{Elevation comparison}

Elevation of the control points acquired based on video data and image data was compared. Results is shown in Table 1. It can be seen that changing trend of the elevation obtained from the two groups is basically the same. The average elevation difference of the 11 control points of the DSM based on video data is $1.38 \mathrm{~m}$ and the standard deviation is 1.34 . While the average elevation difference of the image data is 0.96 and the standard deviation is 0.95 , which is higher than the result of the video data. This is because the frames extracted from the video data have no coordinate information, so that the accuracy of the result completely depends on the number, distribution and accuracy of the ground control points. In the contrast, aerial image data has GPS positioning information and can play a supporting role in aerial triangulation to achieve higher accuracy.

Table1 Elevation accuracy comparison

\begin{tabular}{|c|c|c|c|c|c|}
\hline \multirow{2}{*}{$\begin{array}{l}\text { Verifi } \\
\text { cation } \\
\text { points }\end{array}$} & \multirow{2}{*}{$\begin{array}{l}\text { Elevatio } \\
\text { n of the } \\
\text { Control } \\
\text { points } \\
/ \mathrm{m}\end{array}$} & \multicolumn{2}{|c|}{$\begin{array}{l}\text { Video }+ \text { Ground } \\
\text { control points }\end{array}$} & \multicolumn{2}{|c|}{$\begin{array}{c}\text { Aerial image data } \\
+ \text { Ground control } \\
\text { points }\end{array}$} \\
\hline & & $\begin{array}{c}\text { Absolut } \\
\mathrm{e} \\
\text { elevatio } \\
\mathrm{n} / \mathrm{m}\end{array}$ & $\begin{array}{c}\text { Elevatio } \\
\mathrm{n} \\
\text { differen } \\
\text { ce } / \mathrm{m} \\
\end{array}$ & $\begin{array}{c}\text { Absolut } \\
\mathrm{e} \\
\text { elevatio } \\
\mathrm{n} / \mathrm{m}\end{array}$ & $\begin{array}{c}\text { Elevat } \\
\text { ion } \\
\text { differe } \\
\text { nce } / \mathrm{m}\end{array}$ \\
\hline A1 & 1005 & 1004.65 & -0.35 & 1005.53 & 0.53 \\
\hline A2 & 1001 & 1001.41 & 0.41 & 1001.07 & 0.07 \\
\hline $\mathrm{A} 3$ & 997 & 999.24 & 2.24 & 999.54 & 2.54 \\
\hline A4 & 999 & 1001.73 & 2.73 & 1000.38 & 1.38 \\
\hline A5 & 994 & 995.22 & 1.22 & 994.26 & 0.26 \\
\hline A6 & 999 & 1001.88 & 2.88 & 999.31 & 0.31 \\
\hline A7 & 1000 & 1001.53 & 1.53 & 1000.26 & 0.26 \\
\hline A8 & 1002 & 1003.28 & 1.28 & 1002.84 & 0.84 \\
\hline A9 & 1000 & 1003.44 & 3.44 & 1000.39 & 0.39 \\
\hline $\mathrm{A} 10$ & 1008 & 1008.37 & 0.37 & 1010.86 & 2.86 \\
\hline A11 & 1023 & 1022.41 & -0.59 & 1024.15 & 1.15 \\
\hline $\begin{array}{c}\text { Avera } \\
\text { ge } \\
\text { value }\end{array}$ & -- & -- & 1.38 & -- & 0.96 \\
\hline $\begin{array}{c}\text { Stand } \\
\text { ard } \\
\text { deviat } \\
\text { ion }\end{array}$ & -- & -- & 1.34 & -- & 0.95 \\
\hline
\end{tabular}

\subsection{Terrain factors extraction and comparison}

Slope stability is very important for mine safety. Shape and scale of the slope directly affect the stability of the slope and sometimes it even plays a decisive role [12-13]. Topographic factors affecting the slope stability usually include slope, aspect, topographic relief amplitude, surface roughness, etc.

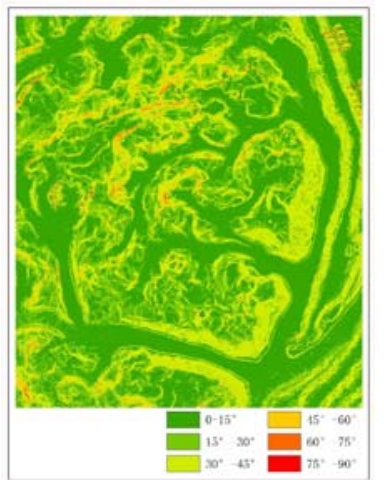

$\mathrm{a}(1)$

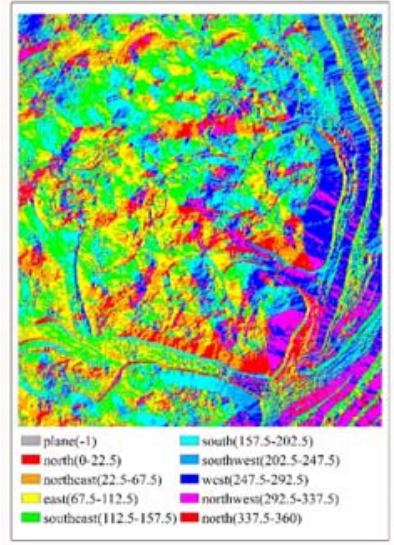

$\mathrm{a}(2)$

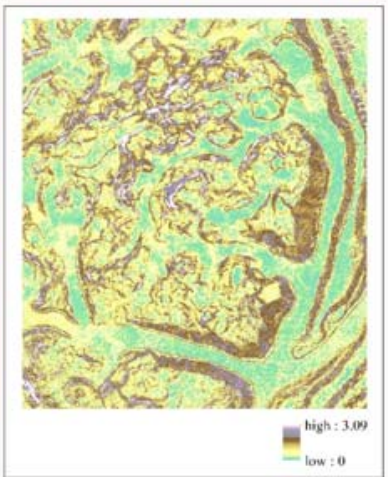

$\mathrm{a}(3)$

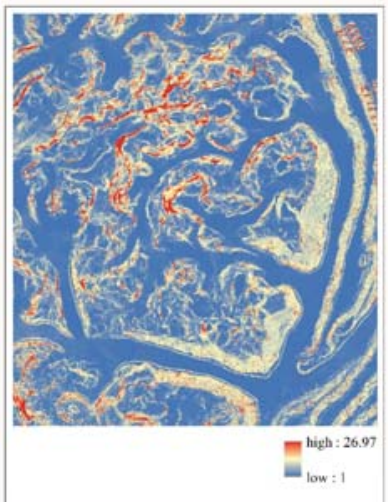

$\mathrm{a}(4)$

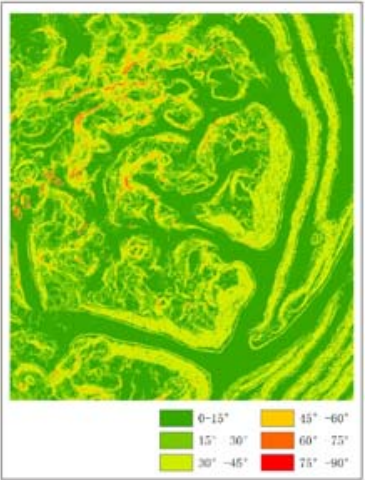

$\mathrm{b}(1)$

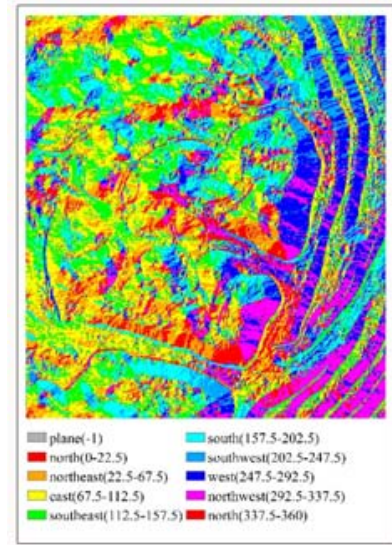

$b(2)$

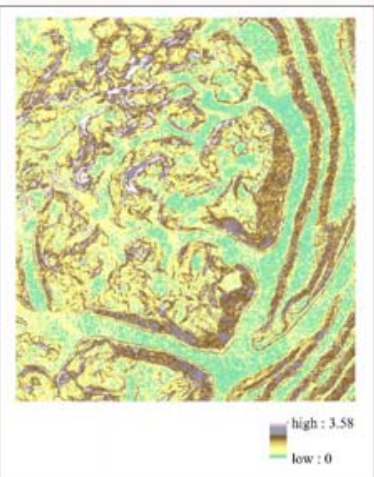

$b(3)$

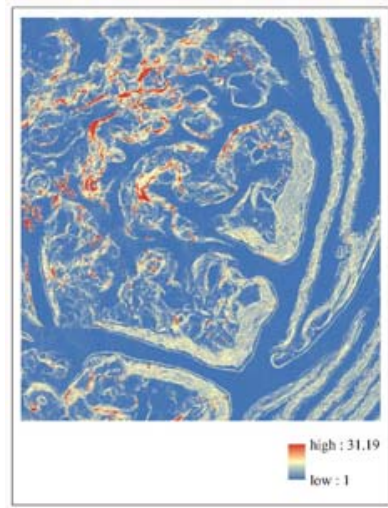

$b(4)$
Fig. 6. The spatial distribution of the terrain factors

The spatial distribution of four terrain factors--slope, topographic relief amplitude (the difference between the maximum elevation and the minimum elevation) and 
surface roughness, were extracted from the DSM of the two sets of data. Fig. $6 \mathrm{a}$ is the result of video data, and Fig. $6 \mathrm{~b}$ is the extraction of image data. As shown in Fig. $6 \mathrm{a}(1)$ and $6 \mathrm{~b}(1)$, the extracted slope factor is classified into six grades: $0-15^{\circ}, 15^{\circ}-30^{\circ}, 30^{\circ}-45^{\circ}, 45^{\circ}-60^{\circ}, 60^{\circ}$ $-75^{\circ}, 75^{\circ}-90^{\circ}$. As shown in Fig. $6 a(2)$ and $6 \mathrm{~b}(2)$, the aspect factor is classified into 10 categories, including plane, north, northeast, east, southeast, south, southwest, west, northwest and north. Using color band, the topographic relief amplitude and surface roughness factors are stretched from minimum value to maximum value to distinguish the numerical rank with different colors, which is shown in Fig. 6a(3), 6b(3), 6a(4) and $6 \mathrm{~b}(4)$, respectively.

It can be seen from Fig. 6 that the terrain factors obtained from the two data sources show similar spatial distribution characteristics. For the result of video data, there are abnormal value at the northeast corner of the study area because of the excavator equipment. The terrain factors obtained from two data sources were numerically analysed.

Numerical analysis was done to the terrain factors obtained from two data sources, in order to calculate the percentage of different grades for each terrain factor in the total study area, as shown in Table 2. From the table, it can be seen that terrain factors are graded in the same way for the two data sources, and the percentages of the same grades are basically the same.

Table 2. Statistic of the terrain factors

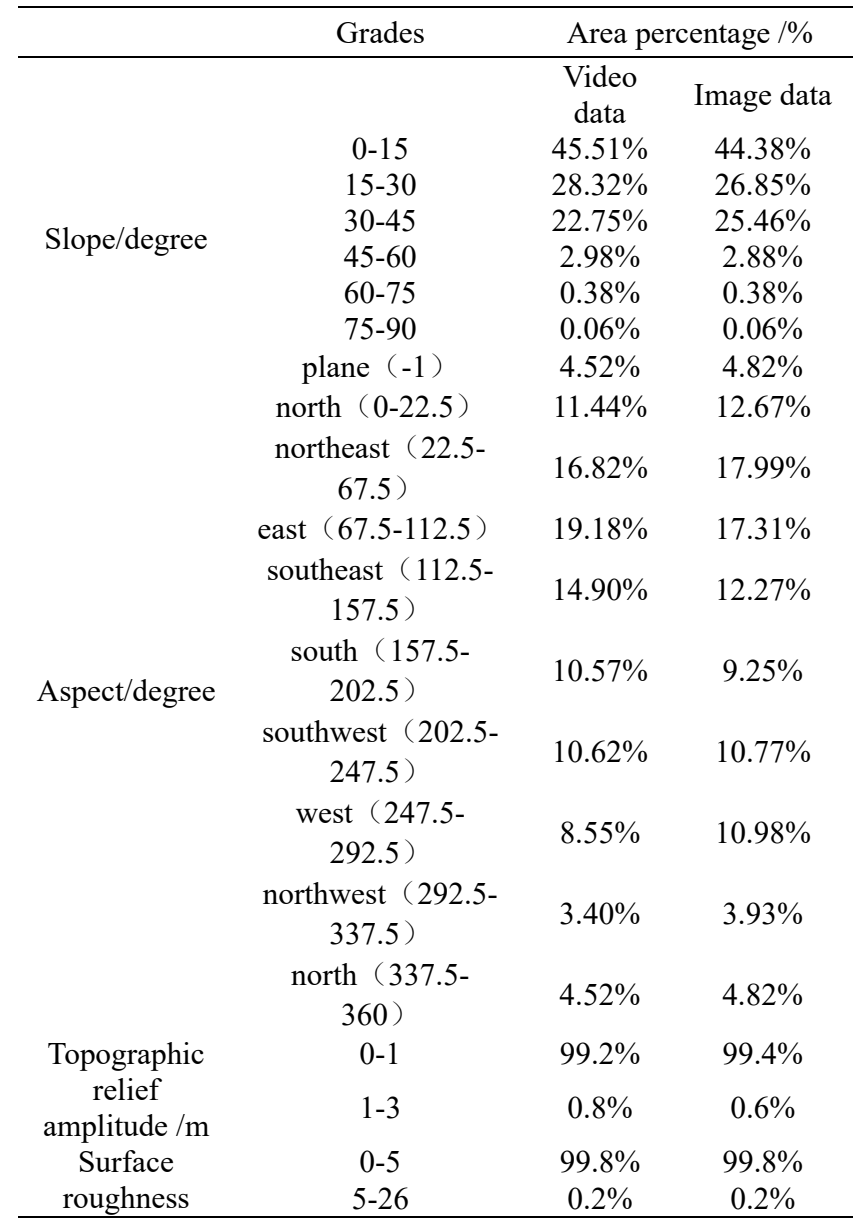

Slope, topographic relief amplitude, and surface roughness are the direct factors affecting slope stability. The steeper the slope is, the greater the height difference will be, and the more complex the topographic conditions, the more likely the slope destabilization will occur [14].

On the whole, the slope in the mining area is mainly $15^{\circ}-45^{\circ}$, and the height difference is mainly $0-1 \mathrm{~m}$. The high and steep slopes of $45^{\circ}-90^{\circ}$ are mainly distributed in the central and northwest of the mine (as shown in Fig. $a(1), b(1))$. This area also has large height difference and complex terrain, with a maximum height difference of about $3 \mathrm{~m}$. Therefore, it is a potential prone area for geological hazards in the research area, so attention should be paid to the prevention and control of landslide and collapse in the area to ensure the safety of operators and equipment.

Slope aspect is an indirect factor that affects the slope stability. It determines the sun and the wind conditions of the slope, which affects the intensity of solar radiation and the degree of weathering, thus affecting its stability [].The slope aspect of the area is mainly concentrated in the east and southeast directions $\left(65.5^{\circ}-157.5^{\circ}\right)$, followed by the northeast, south, southwest and west directions, with an average distribution. The wind direction of Xiaoyi city is mainly southwest and northwest, so the slope of this wind direction is greatly eroded by wind and rain, so it is necessary to pay attention to the instability of the high steep slope in this direction.

\section{Conclusion}

This article selects Xiangwang aluminum mine in Luliang City, Shanxi Province as the research object and uses the DJi inspire 2 model UAV to obtain the video and image data of the research area. Based on the two kinds of data sources, the DSM of the mining area is obtained with or without the ground control points. Following conclusions can be drawn by comparing and analyzing the elevation and the terrain factors of the DSM acquired by the two data sources in the qualitative and quantitative aspects.

The DSM acquired by ContextCapture software without the ground control points, using the video data obtained through flying around the points of interests, can qualitatively reflect the distribution of the topography and have great application potential in the field where the terrain accuracy requirements are not high and have the demand for emergency response to the dynamic change of the land surface. The DSM data obtained by the method using the ground control points can achieve the similar elevation accuracy with the aerial image data. And the terrain factors of the two data sources have similar characteristics in spatial and numerical distribution. Through the comparison and analysis of the terrain factors, it can be concluded that the northwest of the central of the mine is the steep slope distribution area with complex terrain and large elevation difference. Northwest and southwest slopes in this area are more likely to be eroded by wind and rain. 
Therefore, more attentions should be payed to the slope stability monitoring and disaster prevention of this area.

\section{Acknowledgement}

Fund project: The work is jointly supported by Application Research Project of "High Resolution Dynamic Monitoring Camera and Monitoring Technology" High-speed Real-time Data in the Field of Land and Resources, Remote Sensing Geological Survey and Monitoring of National Mine Environmental Restoration and Control Project(DD20190705).

\section{References}

1. Y C. Chen, Y F. Chang, M P. Zheng Mineral resources status in China and strategy for sustainable supply 1-3 (2002)

2. H Z. Huang Three-dimensional Space-time comparative and micro-geomorphological analysis of the open-pit mine based on UAV (2018)

3. M. Liu Application of UAV aerial photogrammetry technology in mine surveying 36 (2019)

4. T. Sui, W Xiao, D C. Wang, X. Wang, S S. Tian Establishment of the 3D model of open-pit mine dump based on UAV photogrammetry 135-142 (2018)

5. X. Fang, Z L. Zhang, L G. Wang, X R. Cui, J Z. Li 3D model reconstruction technology of open-pit mine based on UAV aerial survey 34, 31-34 (2019)

6. C. Tian, J Chen, N N. Li, Y H. Guo Quickly constructing high-precision DSM using image-free control of UAV 158-160 (2017)
7. A D. Gong, X Y. He, T J. Lei, J. Li Fast image processing method of UAV without control data 12, 254-260 (2010)

8. M X. Xie, D D. Tao The application of unmanned aerial survey technology in mine topographic mapping 45-46 (2019)

9. X. Huang, Y. He, W S. Xue Study on the application of UAV aerial technology in waterway survey and design 98 (2017)

10. Songliao Water Resources Commission Songliao River Basin Soil and Water Conservation Monitoring Center. Application of UAV telemetry technology in soil and water conservation supervision 73-76 (2015)

11. L. Zhou, Q X. Li, F. Quan, 3D model and accuracy evaluation of Tilt photogrammetry based on UAV 17 (2020)

12. S G. Du Method of equal accuracy assessment for the stability analysis of large open-pit mine slopes 37, 1301-1331 (2018)

13. L. Doumbouya, C S. Guan, V M. Bowa Influence of Rainfall Patterns on the Slope Stability of the Lumwana (the Malundwe) Open Pit 38, (2020)

14. S G. Sun, Z H. Su, Y H. Zhang GIS-based approach of rock slope's stability assessment under multiple factors 47-52 (2016) 